\title{
Evaluation of a Potential Metabolism-Mediated Drug-Drug Interaction Between Atomoxetine and Bupropion in Healthy Volunteers
}

Ioana Todor ${ }^{1}$, Adina Popa ${ }^{2}$, Maria Neag ${ }^{3}$, Dana Muntean ${ }^{1}$, Corina Bocsan ${ }^{3}$, Anca Buzoianu ${ }^{3}$, Laurian Vlase ${ }^{1}$, Ana-Maria Gheldiu $^{1}$, Corina Briciu ${ }^{2}$

${ }^{1}$ University of Medicine and Pharmacy "Iuliu Hatieganu”, Faculty of Pharmacy, Department of Pharmaceutical Technology and Biopharmaceutics, Cluj-Napoca, Romania. ${ }^{2}$ University of Medicine and Pharmacy "Iuliu Hatieganu", Faculty of Pharmacy, Department of Clinical Pharmacy, Cluj-Napoca, Romania. ${ }^{3}$ University of Medicine and Pharmacy, "Iuliu Hatieganu", Faculty of Medicine, Department of Pharmacology, Toxicology and Clinical Pharmacology, Cluj-Napoca, Romania.

Received, May 3, 2016; Revised, May 25, 2016; Accepted, May 26, 2016; Published, May 28, 2016.

ABSTRACT- Purpose: To evaluate the impact of bupropion on the pharmacokinetic profile of atomoxetine and its main active metabolite (glucuronidated form), 4-hydroxyatomoxetine- $O$-glucuronide, in healthy volunteers. Methods: An open-label, non-randomized, two-period, sequential clinical trial was conducted as follows: during Period I (Reference), each volunteer received a single oral dose of $25 \mathrm{mg}$ atomoxetine, whilst during Period II (Test), a combination of $25 \mathrm{mg}$ atomoxetine and $300 \mathrm{mg}$ bupropion was administered to all volunteers, after a pretreatment regimen with bupropion for 7 days. Next, after determining atomoxetine and 4-hydroxyatomoxetine$O$-glucuronide plasma concentrations, their pharmacokinetic parameters were calculated using a noncompartmental method and subsequently compared to determine any statistically significant differences between the two periods. Results: Bupropion intake influenced all the pharmacokinetic parameters of both atomoxetine and its metabolite. For atomoxetine, $C_{\max }$ increased from $226 \pm 96.1$ to $386 \pm 137 \mathrm{ng} / \mathrm{mL}$ and more importantly, $\mathrm{AUC}_{0-\infty}$ was significantly increased from $1580 \pm 1040$ to $8060 \pm 4160 \mathrm{ng} * \mathrm{~h} / \mathrm{mL}$, while the mean $\mathrm{t}_{1 / 2}$ was prolonged after bupropion pretreatment. For 4-hydroxyatomoxetine- $O$-glucuronide, $\mathrm{C}_{\max }$ and $\mathrm{AUC}_{0-\infty}$ were decreased from $707 \pm 269$ to $212 \pm 145 \mathrm{ng} / \mathrm{mL}$ and from $5750 \pm 1240$ to $3860 \pm 1220 \mathrm{ng} * \mathrm{~h} / \mathrm{mL}$, respectively. Conclusions: These results demonstrated that the effect of bupropion on CYP2D6 activity was responsible for an increased systemic exposure to atomoxetine (5.1-fold) and also for a decreased exposure to its main metabolite (1.5-fold). Additional studies are required in order to evaluate the clinical relevance of this pharmacokinetic drug interaction.

This article is open to POST-PUBLICATION REVIEW. Registered readers (see "For Readers") may comment by clicking on ABSTRACT on the issue's contents page.

\section{INTRODUCTION}

Atomoxetine is a highly selective norephinephrine presynaptic reuptake inhibitor approved as a nonstimulant drug for the management of attention deficit hyperactivity disorder (ADHD) in children, adolescents and adults $(1,2)$. This agent is rapid and well-absorbed after oral administration and has a bioavailability that ranges from 63 to $94 \%$. After oral intake, it reaches a peak plasma concentration in approximately 1 to 2 hours and is highly protein bound ( 98-99 \%) (3-5). Three pathways are involved in the metabolism of atomoxetine: aromatic ring-hydroxylation, benzylic hydroxylation and $\mathrm{N}$ demethylation. 4-hydroxyatomoxetine, the equipotent primary metabolite of atomoxetine, is the result of aromatic ring-hydroxylation, a process mediated by CYP2D6 isoenzyme. Further transformation for this compound occurs via glucuronidation, resulting in 4-hydroxyatomoxetine$O$-glucuronide $(4,6)$. The polymorphism of CYP2D6 divides the individuals taking this nonstimulant medication in two groups, respectively extensive metabolizers (EMs - over $90 \%$ of the population) and poor metabolizers (PMs - approximately 7\% of population) (3). As a result of a much slower hepatic metabolism, the average steady-state plasma

\footnotetext{
Corresponding Author: Laurian Vlase, University of Medicine and Pharmacy "Iuliu Hatieganu", Faculty of Pharmacy, Department of Pharmaceutical Technology and Biopharmaceutics, Victor Babes 41, RO-400012, Cluj-Napoca, Romania, email: vlaselaur@yahoo.com; laurian.vlase@umfcluj.ro.
} 
concentrations of atomoxetine are about 10-fold higher in PMs than in EMs (4). The mean plasma elimination half-lives $\left(t_{1 / 2}\right)$ of atomoxetine and its active metabolite vary between the two populations. In EMs, atomoxetine has a $t_{1 / 2}$ of $5.2 \mathrm{~h}$ and 4hydroxyatomoxetine of 6-8 h, meanwhile, in PMs, the $t_{1 / 2}$ of the two compounds are $21 \mathrm{~h}$ for the parent drug and $19 \mathrm{~h}$ for its hydroxylated metabolite $(3,4)$. The majority of the atomoxetine dose is excreted as a glucuronide conjugate in the urine $(80 \%)$ and feces $(18 \%)$, while less than $3 \%$ is eliminated unchanged $(1,3,4)$.

Bupropion is a second-generation antidepressant with a dual mechanism of action, involving inhibition of norepinephrine and dopamine reuptake. It does not affect serotonin or postsynaptic receptors (7-9). This agent is an approved pharmacological option for the treatment of major depressive disorder (MDD) and nicotine dependence in the United States (US) and several European countries (7). It also has important off-label uses like sexual dysfunction induced by selective serotonin reuptake inhibitors (SSRI), neuropathic pain and ADHD (10). The biotransformation process of bupropion leads to three active metabolites, respectively hydroxybupropion, threohydrobupropion and erythrohydrobupropion $(7,11)$. The most important metabolite, hydroxybupropion, is considered to be half as potent as the parent drug (11). The main enzyme involved in the metabolism of bupropion, CYP2B6 $(7,10,12)$, catalyzes the formation of the main metabolite, whereas the other two metabolites are formed by reduction of the ketonic side chain $(9,11)$. The $t_{1 / 2}$ of bupropion is $20-21 \mathrm{~h}$, meanwhile the metabolites have $t_{1 / 2}$ values either similar or longer than the parent drug (12). The majority of the parent drug and its metabolites is largely eliminated by the kidneys in the urine (10).

Bupropion is a potent inhibitor of CYP2D6 (13), which increases the risk of interacting with drugs metabolized via this isoenzyme, like atomoxetine. Therefore, the aim of this study was to investigate a potential pharmacokinetic interaction between atomoxetine, a substrate of CYP2D6 and bupropion, an enzymatic inhibitor of the same metabolic pathway. The results of this research will provide practitioners with a valuable insight regarding the actual potential for interaction between atomoxetine and a CYP2D6 inhibitor (bupropion) and will contribute to a broader view of the safety profile of this drug. Furthermore, it addresses a safety concern that should be taken into consideration in patients diagnosed with both ADHD and major depressive disorder.

\section{METHODS}

\section{Subjects}

The Ethics Committee of the University of Medicine and Pharmacy "Iuliu Hatieganu", Cluj-Napoca, Romania, reviewed and approved the clinical protocol. In addition, each subject gave a written informed consent prior to any study procedure. The study was conducted in accordance with the principles of Helsinki (1964) and its amendments (Tokyo 1975, Venice 1983, Hong Kong 1989) and Good Clinical Practice (GCP) rules.

Twenty healthy volunteers were included in this study. Caucasian, non-smoking males and females, aged between 18 and 55 years, whose health status was established based on their medical history, physical examination and clinical laboratory tests, were considered eligible subjects. They had no history of alcohol or substance abuse.

\section{Study design}

This was an open-label, non-randomized, sequential clinical study with a two-period design. During Period I (Reference), a single oral dose of $25 \mathrm{mg}$ atomoxetine was administered to each subject, whereas during Period II (Test), the healthy volunteers received a single oral dose of $25 \mathrm{mg}$ atomoxetine coadministered with $300 \mathrm{mg}$ bupropion. Between the two study periods, the subjects were treated with a daily dose of $150 \mathrm{mg}$ bupropion for 3 days, respectively $300 \mathrm{mg}$ bupropion for another 4 days, in order to quickly reach the desired concentration. On days 1 and 9 the subjects remained at the clinical research unit until 12 hours after drug administration, where they received standardized meals at 3, 6 and 10 hours after drug intake. Water intake was restricted 1 hour before and two hours after atomoxetine dosing. All the drugs were administered in the morning, in fasted state and with at least $150 \mathrm{~mL}$ water. No consumption of alcohol or any beverages or foods containing methylxanthines (coffee, tea, cola etc.) was permitted from 48 hours prior to the first drug administration and until the collection of last blood sample of the respective study period. Drugs (other than the study medication, except for oral contraceptives), smoking and alcohol were not allowed to be taken during the course of the trial. Alcohol, smoking or intake of any other 
medication (except the study drugs and oral contraceptives) was not allowed throughout the trial.

The pharmaceutical products used were Strattera (atomoxetine hydrochloride, $25 \mathrm{mg}$ capsules; Lilly USA, LLC Indianapolis, USA) and Elontril (bupropion hydrochloride, 150 and $300 \mathrm{mg}$ tablets; Glaxo Wellcome $\mathrm{GmbH} \&$ Co., Bad Oldesloe, Germany).

\section{Blood plasma samples collection and analysis}

Venous blood $(5 \mathrm{ml})$ was drawn into heparinized tubes, in the first (Reference) and the last day of the study (Test), prior to drug administration, as well as at $0.5,1,1.5,2,2.5,3,4,6,8,10,12,24,36$ and 48 $\mathrm{h}$ after and the separated plasma was stored frozen ($20^{\circ} \mathrm{C}$ ) until analysis. A validated high-throughput liquid chromatography-mass spectrometry (HPLC/MS) method was used to determine the plasma concentrations of atomoxetine and the glucuronidated form of its active hydroxylated metabolite. The chromatographic system was an Agilent 1100 series (binary pump, autosampler, thermostat; Agilent Technologies, Santa Clara, CA, USA) coupled with a Brucker Ion Trap SL (Brucker Daltonics GmbH, Bremen, Germany). Also, the chromatographic column used was a Zobrax SB-C18 (100 mm x $3.0 \mathrm{~mm}$ i.d, $3.5 \mu \mathrm{l}$; Agilent Technologies) and the mobile phase consisted of $2 \mathrm{mM}$ ammonium formate solution and acetonitrile mixture, elution in gradient: $11 \%$ acetonitrile at start, $41 \%$ at 2 minutes. The flow rate was $1 \mathrm{~mL} / \mathrm{min}$ and the thermostat temperature was set at $48^{\circ} \mathrm{C}$. The mass spectrometry detection was in single ion monitoring mode, positive ions, using an electrospray ionization source. The ions monitored were $\mathrm{m} / \mathrm{z} 256$ for atomoxetine and $\mathrm{m} / \mathrm{z} 448$ for its glucuronidated metabolite. The retention times for the parent drug and 4-hydroxyatomoxetine- $O$-glucuronide were 4.1 $\min$ and $2.2 \mathrm{~min}$, respectively. Furthermore, the calibration curves for both compounds were linear between $8-600 \mathrm{ng} / \mathrm{mL}$. The analytical method was validated in terms of specificity, linearity, intra- and inter-day precision, accuracy and analyte recovery. The calibration curves for both compounds were linear between 8-600 $\mathrm{ng} / \mathrm{mL}$, with correlation coefficients (r) $0.9951 \pm 0.0016$ (mean \pm S.D., $\mathrm{n}=5$ ) for atomoxetine and $0.9982 \pm 0.0018$ for its glucuronidated metabolite. For atomoxetine, intraand inter-day precision was less than $8.2 \%$, the accuracy (bias) less than $11.5 \%$ and the recovery ranged between $89-103 \%$, respectively. For 4hydroxyatomoxetine-O-glucuronide, intra- and inter-day precision was less than $10.7 \%$, the accuracy less than $9.3 \%$ and the recovery ranged between $91-105 \%$, respectively.

\section{Pharmacokinetic analysis}

A noncompartmental approach was used to determine the pharmacokinetic parameters for atomoxetine and the glucuronidated form of 4hydroxyatomoxetine, its active metabolite. For both atomoxetine and its metabolite, all the parameters were calculated during Period I (Reference), when atomoxetine was administered alone, as well as during Period II (Test), when atomoxetine was administered concurrently with bupropion, after a pretreatment regimen with the enzymatic inhibitor. The maximum plasma concentration $\left(\mathrm{C}_{\max }, \mathrm{ng} / \mathrm{ml}\right)$ and the corresponding time to reach this concentration $\left(t_{\max }, h\right)$ were obtained directly from the observed concentration-time data. The area under the concentration-time curve $\left(\mathrm{AUC}_{0-\mathrm{t}}\right)$ was estimated using linear trapezoidal rule. The area was extrapolated to infinity $\left(\mathrm{AUC}_{0-\infty}\right)$ by addition of $\mathrm{C}_{t} / \mathrm{k}$ to $\mathrm{AUC}_{0-\mathrm{t}}$, where $\mathrm{C}_{\mathrm{t}}$ represents the estimated concentration at time $\mathrm{t}$ and $\mathrm{k}$ is the elimination rate constant. The latter was estimated by the least-square regression of plasma concentration-time data points lying in the terminal region by using semilogarithmic dependence that corresponds to firstorder kinetics. The elimination half-life was calculated by using the following equation: $t_{1 / 2}=$ 0.693/k.

Phoenix WinNonlin version 6.3 (Pharsight Co., Mountain View, CA, USA) software was used in order to determine all the pharmacokinetic parameters.

\section{Phenotype analysis}

The $\mathrm{AUC}_{0-\infty}$ metabolic ratio of atomoxetine/4hydroxyatomoxetine- $O$-glucuronide was used to identify potential PMs and to further exclude them from the final analysis. This was performed for each subject and subsequently, the lower values were attributed to the EM phenotype, whereas the higher values were associated with the PM phenotype.

\section{STATISTICAL ANALYSIS}

The analysis of variance (ANOVA) was applied to compare the pharmacokinetic parameters of atomoxetine and its active metabolite (glucuronidated form), between the two treatment periods (Test/Reference). General linear model 
procedures were used and the sources of variation were subjects and period of treatment. This statistical approach was employed for all pharmacokinetic parameters, except $t_{\max }$. For the latter one, a nonparametric alternative (Friedman test) was performed to test for differences between the values corresponding to each study period.

The existence of potential clinical consequences following the concomitant administration of atomoxetine and bupropion was assessed by using the bioequivalence methodology. The $90 \%$ confidence intervals $(90 \% \mathrm{CIs})$ of the Test/Reference period ratios for $\mathrm{C}_{\max }, \mathrm{AUC}_{0-\mathrm{t}}$ and $\mathrm{AUC}_{0-\infty}$ (log transformed) were calculated using Schuirmann's two one-sided $t$ test, considering a bioequivalence range from 0.80 to 1.25 . Regarding the analysis of $t_{\max }$, the equivalence range was expressed as untransformed data and significance was established using the non-parametric Friedman test.

Phoenix WinNonlin version 6.3 (Pharsight Co., Mountain View, CA, USA) was also the software used for the statistical analysis. A p value less than 0.05 was considered to be statistically significant.

\section{RESULTS}

\section{Phenotype analysis}

Based on the $\mathrm{AUC}_{0-\infty}$ metabolic ratios (parent drug/metabolite), 2 subjects were identified as potential PMs (data not shown) and were subsequently analyzed separately. As the main purpose of the study was not to investigate the phenotype impact upon atomoxetine pharmacokinetics, but to evaluate a potential interaction between atomoxetine and bupropion, our final analysis was centered on the EM group.

\section{Pharmacokinetics}

The mean plasma concentration-time profiles of atomoxetine and its glucuronidated active metabolite, 4-hydroxyatomoxetine- $O$-glucuronide, when administered alone or in combination with bupropion, after 7 days pretreatment with the enzymatic inhibitor, are presented in Figure 1 (atomoxetine) and Figure 2 (4-hydroxyatomoxetine$O$-glucuronide), respectively. The graphical representations represent the data corresponding to each metabolizer status.

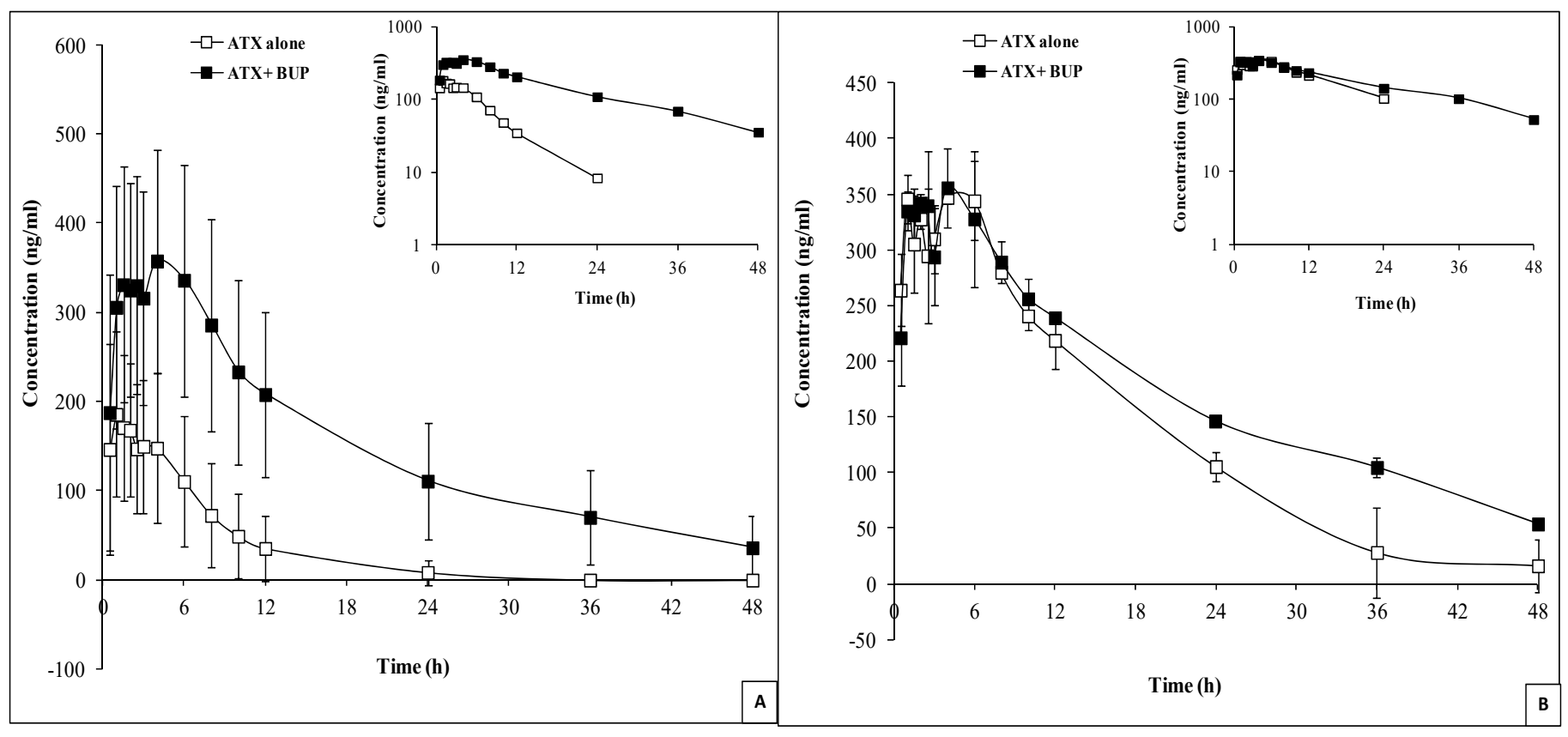

Figure 1. Mean ( \pm SD) plasma levels of atomoxetine (ATX), after a single oral dose of ATX $25 \mathrm{mg}$, before and after 7 days pretreatment with bupropion (BUP) 150-300 mg/day. Insert: semilogarithmic presentation; A - extensive metabolizers (EMs, $\mathrm{n}=18$ ); $\mathrm{B}$ - poor metabolizers (PMs, $\mathrm{n}=2$ ). 
In addition to the graphic results, the mean pharmacokinetic parameters for atomoxetine and its metabolite are shown in Table $\mathbf{1}$ (atomoxetine) and Table 2 (4-hydroxyatomoxetine- $O$-glucuronide). These tables contain the calculated pharmacokinetic parameters corresponding to Period I (Reference), when atomoxetine was taken alone, as well as those affiliated to Period II (Test), when atomoxetine was associated with bupropion and the results of the statistical analysis. The values are presented separately considering each phenotype status.
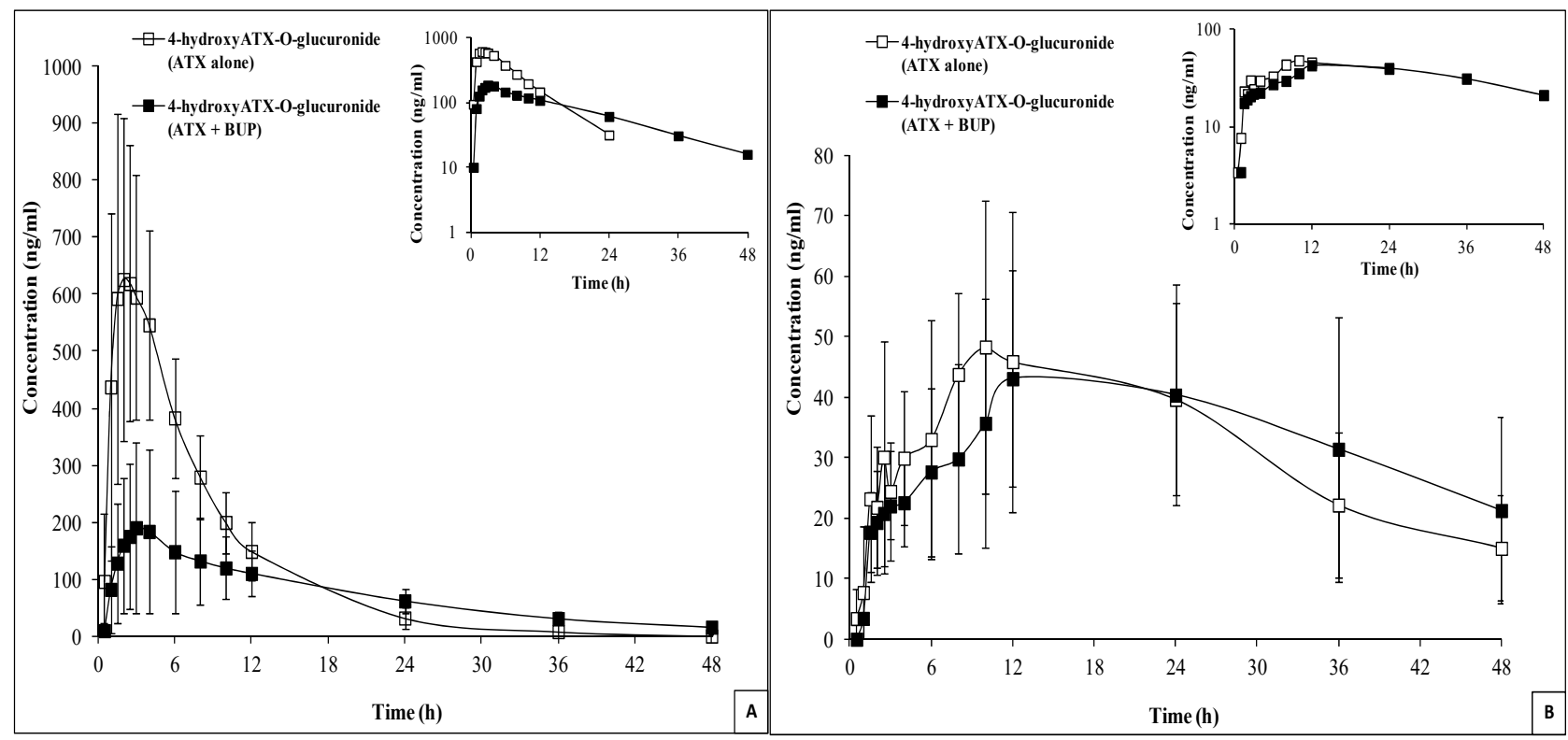

Figure 2. Mean ( $\pm \mathrm{SD}$ ) plasma levels of the active metabolite, 4-hydroxyatomoxetine- $O$-glucuronide (4-hydroxyATX- $O$ glucuronide), after a single oral dose of atomoxetine (ATX) $25 \mathrm{mg}$, before and after 7 days pretreatment with bupropion (BUP) 150-300 mg/day. Insert: semilogarithmic presentation; A - extensive metabolizers (EMs, $\mathrm{n}=18$ ); $\mathrm{B}$ - poor metabolizers (PMs, $\mathrm{n}=2$ ).

Table 1. Pharmacokinetic (PK) parameters of atomoxetine (ATX), after a single oral dose of $25 \mathrm{mg}$ ATX, before and after 7 days pretreatment with bupropion (BUP), in 18 extensive metabolizers (EMs) and 2 poor metabolizers (PMs) and the results of the statistical method (analysis of variance - ANOVA) used for comparison.

\begin{tabular}{|c|c|c|c|}
\hline $\begin{array}{l}\text { PK parameters } \\
(\text { mean } \pm \text { SD })\end{array}$ & $\begin{array}{l}\text { ATX } \\
\text { alone }\end{array}$ & ATX+BUP & $\begin{array}{l}\mathrm{p}^{*} \text { value } \\
\left(\mathrm{ANOVA}^{\mathrm{a}}\right)\end{array}$ \\
\hline \multicolumn{4}{|c|}{ EMs } \\
\hline $\begin{array}{l}\mathrm{C}_{\max }(\mathrm{ng} / \mathrm{mL}) \\
\mathrm{t}_{\max }(\mathrm{h}) \\
\mathrm{AUC}_{0-\mathrm{t}}\left(\mathrm{ng}^{*} \mathrm{~h} / \mathrm{mL}\right) \\
\mathrm{AUC}_{0-\infty}\left(\mathrm{ng}^{*} \mathrm{~h} / \mathrm{mL}\right) \\
\mathrm{k}_{\mathrm{el}}(1 / \mathrm{h}) \\
\mathrm{t}_{1 / 2}(\mathrm{~h})\end{array}$ & $\begin{array}{l}226 \pm 96.1 \\
1.67 \pm 1.21 \\
1460 \pm 935 \\
1580 \pm 1040 \\
0.206 \pm 0.103 \\
4.40 \pm 2.49 \\
\end{array}$ & $\begin{array}{l}386 \pm 137 \\
3.31 \pm 2.01 \\
7010 \pm 3280 \\
8060 \pm 4160 \\
0.0605 \pm 0.0376 \\
13.9 \pm 4.65 \\
\end{array}$ & $\begin{array}{l}0.000015, \mathrm{~S} \\
\text { Friedman, S } \\
0.000000, \mathrm{~S} \\
0.000000, \mathrm{~S} \\
0.000006, \mathrm{~S} \\
0.000006, \mathrm{~S} \\
\end{array}$ \\
\hline \multicolumn{4}{|c|}{ PMs } \\
\hline $\begin{array}{l}\mathrm{C}_{\max }(\mathrm{ng} / \mathrm{mL}) \\
\mathrm{t}_{\max }(\mathrm{h})\end{array}$ & $\begin{array}{l}365 \pm 5.48 \\
3.50 \pm 3.53\end{array}$ & $\begin{array}{l}377 \pm 4.27 \\
3.25 \pm 1.06\end{array}$ & $\begin{array}{l}\text { ND** } \\
\text { ND }\end{array}$ \\
\hline $\begin{array}{l}\mathrm{AUC}_{0-\mathrm{t}}\left(\mathrm{ng}^{*} \mathrm{~h} / \mathrm{mL}\right) \\
\operatorname{AUC}_{0-\infty}\left(\mathrm{ng}^{*} \mathrm{~h} / \mathrm{mL}\right) \\
\mathrm{k}_{\mathrm{el}}(1 / \mathrm{h}) \\
\mathrm{t}_{1 / 2}(\mathrm{~h})\end{array}$ & $\begin{array}{l}6140 \pm 1150 \\
7680 \pm 11.3 \\
0.0450 \pm 0.00707 \\
14.8 \pm 0.890\end{array}$ & $\begin{array}{l}8290 \pm 111 \\
9750 \pm 171 \\
0.0400 \pm 0 \\
17.4 \pm 1.69 \\
\end{array}$ & $\begin{array}{l}\text { ND } \\
\text { ND } \\
\text { ND } \\
\text { ND }\end{array}$ \\
\hline
\end{tabular}

*Statistically significant(S) for $\mathrm{p}<0.05 ;{ }^{\mathrm{a}}$ ANOVA except where stated otherwise;

**ND- not determined (only 2 PMs) 
By using the bioequivalence methodology, a comparison was made between the two study periods (Test/Reference) for the following pharmacokinetic parameters: $\mathrm{C}_{\max }, \mathrm{AUC}_{0-\mathrm{t}}, \mathrm{AUC}_{0-\infty}$ and $\mathrm{t}_{\max }$. The $90 \%$
CIs for atomoxetine and 4-hydroxyatomoxetine- $O$ glucuronide and the bioequivalence results are presented in Table 3.

Table 2. Pharmacokinetic (PK) parameters of 4-hydroxyatomoxetine- $O$-glucuronide (4-hydroxyATX-O-glucuronide), after a single oral dose of $25 \mathrm{mg}$ atomoxetine (ATX), before and after 7 days pretreatment with bupropion (BUP), in 18 extensive metabolizers (EMs) and 2 poor metabolizers (PMs) and and the results of the statistical method (analysis of variance - ANOVA) used for comparison.

\begin{tabular}{|c|c|c|c|}
\hline $\begin{array}{l}\text { PK parameters } \\
(\text { mean } \pm \text { SD) }\end{array}$ & $\begin{array}{l}\text { 4-hydroxyATX-O- } \\
\text { glucuronide alone }\end{array}$ & $\begin{array}{l}\text { 4-hydroxyATX-O- } \\
\text { glucuronide + BUP }\end{array}$ & $\begin{array}{l}\mathrm{p}^{*} \text { value } \\
\left(\text { ANOVA }^{\mathrm{a}}\right)\end{array}$ \\
\hline \multicolumn{4}{|c|}{ EMs } \\
\hline$C_{\max }(n g / m L)$ & $707 \pm 269$ & $212 \pm 145$ & $0.000000, \mathrm{~S}$ \\
\hline $\mathbf{t}_{\max }(h)$ & $2.72 \pm 1.34$ & $5.14 \pm 4.02$ & Friedman, $\mathrm{S}$ \\
\hline $\operatorname{AUC} 0-\mathrm{t}\left(\mathrm{ng}{ }^{*} \mathbf{h} / \mathrm{mL}\right)$ & $5620 \pm 1230$ & $3490 \pm 1270$ & $0.000029, \mathrm{~S}$ \\
\hline $\operatorname{AUC}_{0-\infty}(\mathbf{n g} * \mathbf{h} / \mathbf{m L})$ & $5750 \pm 1240$ & $3860 \pm 1220$ & $0.000033, \mathrm{~S}$ \\
\hline$k_{\text {el }}(1 / h)$ & $0.129 \pm 0.0336$ & $0.0577 \pm 0.0207$ & $0.000023, \mathrm{~S}$ \\
\hline $\mathbf{t}_{1 / 2}(\mathbf{h})$ & $5.67 \pm 1.63$ & $13.5 \pm 5.06$ & $0.000000, \mathrm{~S}$ \\
\hline \multicolumn{4}{|c|}{ PMs } \\
\hline $\mathrm{C}_{\max }(\mathrm{ng} / \mathrm{mL})$ & $49.8 \pm 22.1$ & $43.0 \pm 17.9$ & ND** \\
\hline$t_{\max }(h)$ & $9.00 \pm 1.41$ & $12.0 \pm 0$ & ND \\
\hline $\operatorname{AUC}_{0-\mathrm{t}}(\mathrm{ng} * \mathbf{h} / \mathrm{mL})$ & $1510 \pm 727$ & $1560 \pm 831$ & ND \\
\hline $\operatorname{AUC}_{0-\infty}(\mathbf{n g} * \mathbf{h} / \mathbf{m L})$ & $1880 \pm 1010$ & $2480 \pm 1780$ & ND \\
\hline$k_{\text {el }}(1 / h)$ & $0.0450 \pm 0.00707$ & $0.0300 \pm 0.0141$ & ND \\
\hline$t_{1 / 2}(h)$ & $16.6 \pm 3.34$ & $25.1 \pm 11.2$ & ND \\
\hline
\end{tabular}

*Statistically significant(S) for $\mathrm{p}<0.05$; ${ }^{\text {a ANOVA except where stated otherwise; }}$

**ND- not determined (only 2 PMs)

Table 3. Bioequivalence evaluation of the pharmacokinetic (PK) parameters of atomoxetine (ATX) and its glucuronidated active metabolite (4-hydroxyATX-O-glucuronide), before and after 7 days pretreatment with bupropion, in 18 healthy volunteers (extensive metabolizers - EMs).

\begin{tabular}{llll}
\hline \hline ATX/ AMM & PK parameters & $90 \% \mathrm{CI}^{\mathrm{a}}$ & Bioequivalence conclusion $^{\mathrm{b}}$ \\
\hline ATX & $\mathrm{C}_{\max }$ & $1.49-2.07$ & Bio-ineq \\
& $\mathrm{AUC}_{0-\mathrm{t}}$ & $3.78-6.94$ & Bio-ineq \\
& $\mathrm{AUC}$ & $3.94-7.40$ & Bio-ineq \\
& $\mathrm{t}_{\max }$ & Friedman & Bio-ineq \\
\hline 4-hydroxyATX-O- & & & \\
glucuronide & $\mathrm{C}_{\max }$ & $0.19-0.34$ & Bio-ineq \\
& $\mathrm{AUC}$ & $0.50-0.69$ & Bio-ineq \\
& $\mathrm{AUC}$ & $0.56-0.74$ & Bio-ineq \\
& $\mathrm{t}_{\max }$ & Friedman & Bio-ineq \\
\hline
\end{tabular}

a90\% CI- 90\% confidence intervals; ${ }^{b}$ Bioequivalent if 90\% CI: 0.8-1.25; Bio-ineq.: Bio-inequivalent 


\section{DISCUSSION}

Atomoxetine is considered to be particularly beneficial as an adjunct therapy in ADHD patients presenting tics and comorbid anxiety (14-16). As it is devoid of abuse potential, atomoxetine is regarded as an appropriate alternative to the drugs that are misused (17). Bupropion is primarily acknowledged as an antidepressant and a smoking cessation agent, but also demonstrated its effectiveness for the treatment of ADHD in children and adults, although it is not approved for this indication (18-20). These pharmacological agents are not only linked to the same isoenzyme, as atomoxetine is a substrate (6), while bupropion is an enzymatic inhibitor of CYP2D6 (13), but, equally important, their association in clinical circumstances can be taken into consideration. Adler et al. emphasized that the practice of prescribing a combination of medications is common in adult ADHD and is especially required in cases of partial response, dose-limiting side effects, preexisting or treatment-induced disorders and comorbid diagnoses (21). ADHD is particularly associated with significant lifetime psychiatric comorbidity (22). In the case of comorbid ADHD and MDD, the guidelines recommend the add-on of an antidepressant if the symptoms of depression persist after resolution of ADHD (20). Moreover, a retrospective analysis that included 18.609 adult patients diagnosed with ADHD, revealed that combination therapy is used in real-life practice and that approximately $8 \%$ to $9 \%$ of the combining treatments included the association of stimulants and of atomoxetine with bupropion. Factors like older adults, psychiatric care, having a hyperactive component of ADHD or comorbid depression were predictive for the use of combination therapy in patients receiving atomoxetine (23). Therefore, even though more studies regarding the concomitant use of atomoxetine and bupropion in clinical practice are currently lacking, this combination could be considered as potentially useful in patients diagnosed with both ADHD and MDD. As the clinical context exists, the evaluation of a potential pharmacokinetic interaction between these two drugs can be viewed as imperative.

Since CYP2D6 is characterized by genetic polymorphism, the phenotypic metabolizer status can significantly alter the pharmacokinetics of atomoxetine. More importantly, CYP inhibitors appear to have no impact on the steady-state plasma concentrations of atomoxetine in PMs (4). The results obtained in the present research clearly demonstrate the need to exclude any data corresponding to PMs from the final results because it may decrease the actual magnitude of the pharmacokinetic interaction. Unlike the pharmacokinetic values attributed to EMs, there were minimal changes for all the parameters corresponding to the PM group for atomoxetine and its metabolite (Table 1 and Table 2), when compared between study periods (before and after bupropion pretreatment). Therefore, as it was revealed in our study and in accordance with the scientific literature (24) the drug interaction between a substrate of CYP2D6 and an enzymatic inhibitor of the same metabolic pathway is less visible in PMs as they do not have CYP2D6 enzymes to compete for. For this reason and in order to avoid any interference with the study results, the final outcomes excluded the 2 subjects identified as potential PMs and only referred to the volunteers characterized as EMs (18 subjects).

The results of the present study demonstrated that bupropion had a marked influence upon the pharmacokinetic profile of a single oral dose of atomoxetine. Figure 1 revealed that the mean plasma concentrations of the parent drug were increased after association of atomoxetine and the aforementioned enzymatic inhibitor. As shown in Table 1, exposure to atomoxetine $\left(\mathrm{C}_{\max }, \mathrm{AUC}_{0-\mathrm{t}}\right.$ and $\mathrm{AUC}_{0-\infty}$ ) notably increased after bupropion multipledose treatment, revealing a possible presystemic drug-drug interaction. In comparison to Period I, when atomoxetine was administered as monotherapy, $\mathrm{C}_{\max }$ increased slightly more than 1.7fold after bupropion pretreatment. The calculated values of these pharmacokinetic parameters for $\mathrm{AUC}_{0-\mathrm{t}}$ and $\mathrm{AUC}_{0-\infty}$, were different before and after bupropion pretreatment. More precisely, $\mathrm{AUC}_{0-\mathrm{t}}$ and $\mathrm{AUC}_{0-\infty}$ presented an approximately 4.8 -fold, respectively 5.1-fold increase after bupropion and atomoxetine concomitant intake. In addition, $t_{\max }$ was significantly different between the two periods, thus suggesting that the rate of absorption was also modified. The mean $t_{1 / 2}$ increased by 3.1 -fold, while $\mathrm{k}_{\mathrm{el}}$ underwent a 3.4-fold reduction, which implies that the elimination process of atomoxetine was altered after association with the enzymatic inhibitor and thus exposing a systemic drug-drug interaction between the two agents. In order to compare the present results with findings of similar studies, a literature search identified a clinical trial that investigated the pharmacokinetic interaction between multiple-dose paroxetine, also an inhibitor 
of CYP2D6 and multiple-dose atomoxetine. The study concluded that concomitant intake of paroxetine determined a steady-state $\mathrm{C}_{\max }, \mathrm{AUC}_{0-12}$ and $t_{1 / 2}$ that were 3.5 -fold, 6.5 -fold and 2.5 -fold greater than those attributed to atomoxetine alone (25). Although in comparison to paroxetine, the magnitude of the effect produced by bupropion upon atomoxetine pharmacokinetics was smaller, nevertheless it provides valuable information regarding the potential of interaction of atomoxetine when coadministered with CYP2D6 enzymatic inhibitors.

Regarding the glucuronidated active metabolite of atomoxetine (4-hydroxyatomoxetine- $O$ glucuronide), Figure 2 showed that its mean plasma concentrations were decreased after bupropion coadministration. In addition, the changes suffered by its pharmacokinetic parameters came to confirm the interaction between the two agents. As a result of the enzymatic inhibition, the metabolism of atomoxetine was significantly altered, which was translated into a reduced exposure to its active metabolite. More specifically, $\mathrm{C}_{\max }, \mathrm{AUC}_{0-\mathrm{t}}$ and $\mathrm{AUC}_{0-\infty}$ of 4-hydroxyatomoxetine- $O$-glucuronide demonstrated a 3.3-fold, 1.6-fold and approximately 1.5 -fold reduction after bupropion pretreatment.

Other factors that can affect drug response also need to be considered, including one from a molecular and immunological point of view. Available scientific data support the existence of an inflammatory response in depressive disorders as a correlation between changes in pro-inflammatory cytokines and depression has been established. Although the exact mechanism of this relationship remains to be elucidated, the fact that it can influence drug therapy is already acknowledged (26). Subsequently, when interpreting the results of the present study, a special consideration must be given to the role of inflammation as the alterations of gene expression induced by this process can influence not only transporters, receptors or plasma proteins, but also metabolizing enzymes (27). According to Renton KW et al., an inflammatory response can have an impact upon CYP450 activity which translates into a decrease capacity of the liver to ensure drug metabolism and subsequently, may increase the risk of adverse outcomes. For this reason, we can affirm that the potential inflammatory status can also contribute to enzyme activity alterations which in turn leads to modifications in the effect produced by the CYP2D6 substrate.
As illustrated in Table 1 and 2, all the pharmacokinetic parameters of atomoxetine and its active hydroxylated metabolite (glucuronidated form) presented statistically significant changes between the study periods, which clearly emphasizes the fact that bupropion had a significant impact on atomoxetine pharmacokinetics. Furthermore, the bioequivalence test results shown in Table 3 indicate that the $90 \%$ CIs for all the pharmacokinetic parameters of atomoxetine and 4hydroxyatomoxetine- $O$-glucuronide, during the two study periods, were outside the acceptable limits of bioequivalence $(0.8-1.25)$. Thus, the bioequivalence analysis suggested that the pharmacokinetic interaction between atomoxetine and bupropion may have clinical consequences. Up until now, the information available concerning the potential clinical relevance attributed to interactions between atomoxetine and CYP2D6 inhibitors is limited. The association of atomoxetine and fluoxetine, another potent CYP2D6 inhibitor, was responsible for minimal changes in heart rate and blood pressure (28). Also, coadministration of atomoxetine and paroxetine resulted in tachycardia related to postural changes that was attributed to a possible pharmacodynamic interaction between the two agents and not to the pharmacokinetic interaction related to CYP2D6 inhibition (25). Moreover, reports concerning the correlation between atomoxetine plasmatic level and response to medication is also scarcely found, respectively very few studies have investigated whether the plasma concentrations would predict the clinical effect (29). Previous studies that focused on atomoxetine pharmacokinetics revealed that a maximum response

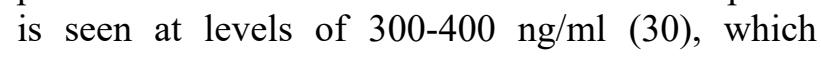
suggest that the mean peak plasma concentrations obtained in the present study, after bupropion pretreatment $(386 \pm 137 \mathrm{ng} / \mathrm{ml})$ can determine a maximum clinical response. Some studies revealed that increased serum levels of atomoxetine were correlated with greater improvement in ADHD symptoms (29). When combined with fluoxetine, another enzymatic inhibitor of CYP2D6, the following mean peak plasma concentrations were obtained for atomoxetine: $1176.7 \pm 565.0 \mathrm{ng} / \mathrm{mL}$ for the group that received atomoxetine + fluoxetine and $351.0 \pm 369.4 \mathrm{ng} / \mathrm{ml}$ for the one subjected to a monotherapy regimen with atomoxetine. In terms of tolerability, the combined treatment, that led to a much higher plasma levels that the ones encountered in our study, had greater increases in blood pressure 
and pulse than the monotherapy group (28). This suggests that it is possible for the combination of atomoxetine and bupropion to be well tolerated. However, other studies have shown that atomoxetine plasma concentration may not be a reliable indicator for therapeutic outcome $(29,30)$. In light of this controversy, precaution is needed when atomoxetine and bupropion are administered concurrently, especially in patients with cardiovascular disorders. Other adverse effects frequently associated with atomoxetine treatment and that should be taken into account include nausea, dry mouth, constipation, urinary hesitation and erectile dysfunction (31).

Therefore, the present research demonstrated that a metabolism-related pharmacokinetic interaction was present between atomoxetine and bupropion, but additional studies are required in order to evaluate the clinical consequences associated with this drug combination. Until then, the results of the present research suggest that caution is needed whenever these agents are to be associated in clinical practice.

\section{Limitations}

A limitation of the present study was the lack of CYP2D6 genotyping data necessary to assess the metabolizer status for each subject included in the study. Nonetheless, another method $\left(\mathrm{AUC}_{0-\infty}\right.$ metabolic ratio atomoxetine/metabolite) was used in order to identify potential PMs, which subsequently permitted their exclusion from the final results. Another limitation refers to the absence of any data regarding the possible clinical significance of this pharmacokinetic interaction.

\section{CONCLUSIONS}

This study demonstrated that multiple-dose bupropion significantly influenced the pharmacokinetics of atomoxetine and its active metabolite (4-hydroxyatomoxetine- $O$-glucuronide). Due to its inhibitory capacity on CYP2D6 enzyme activity, bupropion determined a 5.1-fold increased exposure to atomoxetine and reduced the plasma concentrations of its active metabolite. The clinical relevance of this interaction remains to be established, but until then, safety monitoring of this combination should be recommended.

\section{ACKNOWLEDGEMENTS}

Financial disclosures: This work was supported by the National Research Council (CNCS) Romania project PN-II-ID-PCE-2011-3-0731. All authors are full-time employees of the University of Medicine and Pharmacy "Iuliu Hatieganu", Cluj-Napoca, Romania.

Conflicts of interest: The authors declare no conflict of interest.

\section{REFERENCES}

1. Corman SL, Fedutes BA, Culley CM. Atomoxetine: the first nonstimulant for the management of attention-deficit/hyperactivity disorder. Am J Health Syst Pharm. 2004; 61(22):2391-9.

2. Barton J. Atomoxetine: a new pharmacotherapeutic approach in the management of attention deficit/hyperactivity disorder. Arch Dis Child. 2005; 90 Suppl 1:i26-9. DOI: 10.1136/adc.2004.059386.

3. Aman MG, Smith T, Arnold LE, et al. A review of atomoxetine effects in young people with developmental disabilities. Res Dev Disabil. 2014; 35(6):1412-24. DOI: 10.1016/j.ridd.2014.03.006.

4. Sauer J-M, Ring BJ, Witcher JW. Clinical pharmacokinetics of atomoxetine. Clin Pharmacokinet. 2005; 44(6):571-90. DOI: 10.2165/00003088-200544060-00002.

5. Hammerness P, McCarthy K, Mancuso E, Gendron C, Geller D. Atomoxetine for the treatment of attention-deficit/hyperactivity disorder in children and adolescents: a review. Neuropsychiatr Dis Treat. 2009; 5:215-26. DOI: 10.2147/ndt.s3896.

6. Ring BJ, Gillespie JS, Eckstein JA, Wrighton SA. Identification of the human cytochromes P450 responsible for atomoxetine metabolism. Drug Metab Dispos. 2002; 30(3):319-23. DOI: 10.1124/dmd.30.3.319.

7. Dhillon S, Yang LPH, Curran MP. Bupropion: a review of its use in the management of major depressive disorder. Drugs. 2008; 68(5):653-89. DOI: 10.2165/00003495-200868050-00011.

8. Stahl SM, Pradko JF, Haight BR, Modell JG, Rockett $\mathrm{CB}$, Learned-Coughlin S. A Review of the Neuropharmacology of Bupropion, a Dual Norepinephrine and Dopamine Reuptake Inhibitor. Prim Care Companion J Clin Psychiatry. 2004; 6(4):159-66. DOI: 10.4088/pcc.v06n0403.

9. Saiz Ruiz J, Gibert J, Gutiérrez Fraile M, et al. Bupropion: efficacy and safety in the treatment of depression. Actas españolas Psiquiatr. 2011; 39 Suppl $1: 1-25$.

10. Foley KF, DeSanty KP, Kast RE. Bupropion: 
pharmacology and therapeutic applications. Expert Rev Neurother. 2006; 6(9):1249-65. DOI: 10.1586/14737175.6.9.1249.

11. Škarydová L, Tomanová R, Havlíková L, Štambergová H, Solich P, Wsól V. Deeper Insight into the Reducing Biotransformation of Bupropion in the Human Liver. Drug Metab Pharmacokinet. 2014; 29(2):177-84. DOI: 10.2133/dmpk.dmpk-13-rg051.

12. Dwoskin LP. Rauhut AS. King-Pospisil KA. Bardo M. Review of the pharmacology and clinical profile of bupropion, an antidepressant and tabacco use cessation agent. . CNS Drug Rev. 2006; 12(3):178207. DOI: $10.1111 /$ j.1527-3458.2006.00178.x.

13. Kotlyar M, Brauer LH, Tracy TS, et al. Inhibition of CYP2D6 activity by bupropion. J Clin Psychopharmacol. 2005; 25(3):226-9. DOI: 10.1097/01.jcp.0000162805.46453.e3.

14. Garnock-Jones KP, Keating GM. Atomoxetine: a review of its use in attention-deficit hyperactivity disorder in children and adolescents. Paediatr Drugs. 2009 ; 11(3):203-26. DOI: 10.2165/00148581200911030-00005.

15. Childress AC. A critical appraisal of atomoxetine in the management of ADHD. Ther Clin Risk Manag. 2016; 12:27-39. DOI: 10.2147/tcrm.s59270.

16. Sharma A, Couture J. A Review of the Pathophysiology, Etiology, and Treatment of Attention-Deficit Hyperactivity Disorder (ADHD). Ann Pharmacother. 2014; 48(2):209-25. DOI: 10.1177/1060028013510699.

17. Clemow DB, Walker DJ. The potential for misuse and abuse of medications in ADHD: a review. Postgrad Med. 2014; 126(5):64-81. DOI: 10.3810/pgm.2014.09.2801.

18. Hashemian P, Nazemian A. Evaluation of Bupropion and Venlafaxine in Children with ADHD. J Psychiatry 2015; 18(2):2-4. DOI: 10.4172/psychiatry.1000241.

19. Maneeton N, Maneeton B, Srisurapanont M, Martin SD. Bupropion for adults with attention-deficit hyperactivity disorder: Meta-analysis of randomized, placebo-controlled trials. Psychiatry Clin Neurosci. 2011; 65(7):611-7. DOI: 10.1111/j.14401819.2011.02264.x.

20. Pliszka SR. Pharmacologic treatment of attentiondeficit/hyperactivity disorder: Efficacy, safety and mechanisms of action. Neuropsychol Rev. 2007;17(1):61-72.

21. Adler LA, Reingold LS, Morrill MS, Wilens TE. Combination pharmacotherapy for adult ADHD. Curr Psychiatry Rep. 2006; 8(5):409-15. DOI: 10.1007/s11920-006-0044-9.

22. McGough JJ, Smalley SL, McCracken JT, et al.
Psychiatric comorbidity in adult attention deficit hyperactivity disorder: findings from multiplex families. Am J Psychiatry. 2005; 162(9):1621-7. DOI: 10.1176/appi.ajp.162.9.1621.

23. Pohl GM, Van Brunt DL, Ye W, Stoops WW, Johnston JA. A retrospective claims analysis of combination therapy in the treatment of adult attention-deficit/hyperactivity disorder (ADHD). BMC Health Serv Res. 2009; 9:95. DOI: 10.1186/1472-6963-9-95.

24. Teh LK, Bertilsson L. Pharmacogenomics of CYP2D6: molecular genetics, interethnic differences and clinical importance. Drug Metab Pharmacokinet. 2012; 27(1):55-67. DOI: 10.2133/dmpk.dmpk-11rv-121.

25. Belle DJ, Ernest CS, Sauer JM, Smith BP, Thomasson HR, Witcher JW. Effect of potent CYP2D6 inhibition by paroxetine on atomoxetine pharmacokinetics. J Clin Pharmacol. 2002; 42(11):1219-27. 10.1177/009127002762491307.

26. Kulmatycki KM, Jamali F. Drug disease interactions: role of inflammatory mediators in depression and variability in antidepressant drug response. J Pharm Pharm Sci. 2006; 9(3):292-306. DOI: $10.18433 / \mathrm{j} 36 \mathrm{p} 47$.

27. Hanafy S, El-Kadi AOS, Jamali F. Effect of inflammation on molecular targets and drug transporters. J Pharm Pharm Sci. 2012; 15(3):36175. DOI: $10.18433 / \mathrm{j} 30300$.

28. Kratochvil CJ, Newcorn JH, Arnold LE, et al. Atomoxetine alone or combined with fluoxetine for treating ADHD with comorbid depressive or anxiety symptoms. J Am Acad Child Adolesc Psychiatry. 2005; 44(9):915-24. DOI: 10.1097/01.chi.0000169012.81536.38.

29. Hazell P, Becker K, Nikkanen EA, et al. Relationship between atomoxetine plasma concentration, treatment response and tolerability in attentiondeficit/hyperactivity disorder and comorbid oppositional defiant disorder. Atten Defic Hyperact Disord. 2009; 1(2):201-10. DOI: 10.1007/s12402009-0012-4.

30. Kratochvil CJ, Michelson D, Newcorn JH, et al. High-dose atomoxetine treatment of ADHD in youths with limited response to standard doses. J Am Acad Child Adolesc Psychiatry. 2007; 46(9):1128-37. DOI: 10.1097/chi.0b013e318074eeb3.

31. Camporeale A, Porsdal V, De Bruyckere K, et al. Safety and tolerability of atomoxetine in treatment of attention deficit hyperactivity disorder in adult patients: an integrated analysis of 15 clinical trials. J Psychopharmacol. 2015; 29(1):3-14. DOI: $10.1177 / 0269881114560183$. 